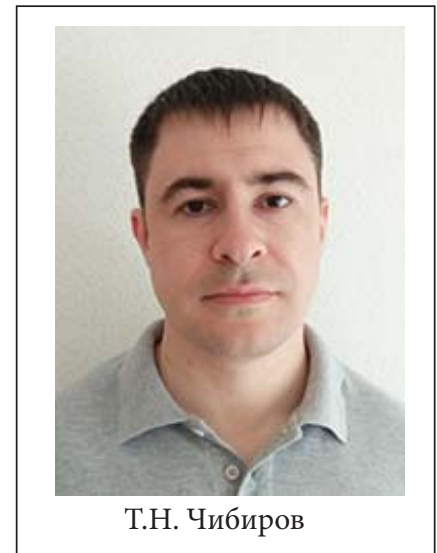

DOI 10.23671/VNC.2018.4.23791

\title{
КОГНИТИВНЫЙ ПРИЗНАК «РАБОЧАЯ ЛОШАДЬ» В СТРУКТУРЕ КОНЦЕПТА «ЛОШАДЬ» В ОСЕТИНСКОЙ, РУССКОЙ И АНГЛИЙСКОЙ ЛИНГВОКУЛЬТУРАХ
}

\section{Т.Н. Чибиров"}

Аннотация. В данной статье рассмотрены различные способы структурной организации концептов, среди которых автором выделяется когнитивный (концептуальный) признак, являющийся, по М.В. Пименовой, структурной единицей ментального образования. В рамках концепта «лошадь» в осетинской, русской и английской лингвокультурах описан когнитивный признак «рабочая лошадь», в ходе рассмотрения которого была выявлена его неравномерная репрезентация в рассматриваемых языковых картинах мира. Сравнительно богатый лексический и фрразеологический материал русского и английского языков репрезентирующий признак «рабочая лошадь» указывает на его принадлежность к ядру, в то время как осетинский язык имеет определенный дефицит лексики подобного рода, а выявленные фрразеологические единицы содержат специфическую коннотацию «несерьезные работы».

Ключевые слова: концепт «лошадь», когнитивный признак, национальная специфика концепта, полевая организация концепта, структура концепта, ядро - периферия.

Концепт - ментальное образование, имеющее сложную структуру. В современной лингвистике нет общего ее понимания, и каждый исследователь посвоему ее интерпретирует. Однако при рассмотрении структуры концепта многие ученые выделяют в нем полевую модель «ядро - периферия» (Н.Ф. Алефиренко, Н.Н. Болдырев, С.Г. Воркачев, М. Джонсон и Дж. Лакофф, Е.С. Кубрякова, В.А. Маслова, З.Д. Попова и И.А. Стернин, В.Н. Телия).

Согласно Н.Н. Болдыреву, «ядро концепта составляют конкретно-образные характеристики, которые являются результатом чувственного восприятия мира» [2, с. 29]. Периферия, как отмечает В.А. Маслова, это ассоциативно образные репрезентации [12, c. 17].

Говоря о структуре концепта, З.Д. Попова и И.А. Стернин отмечают его полевую организацию, которая включает чувственный образ, информационное содержание и интерпретационное поле [18, с. 15].

С.В. Иванова подчеркивает, что «структура концепта включает в себя лингвистическую, когнитивную, культурологическую составляющие и имеет национальную специфику» [8, с. 65].

Видный представитель кемеровской школы М.В. Пименова выделяет наличие концептуальных признаков в структуре концепта [16].

В основе исследования структуры данного концепта лежит семантико-когнитивный подход, который согласно З.Д. Поповой и И.А. Стернину, подчеркивает «соотношения семантики языка с концептосферой народа, соотношения семантических процессов с когнитивными». Ученые отмечают, что через изучение семантики языковых знаков можно проникнуть в концептосфреру [18, с. 13]

Согласно М.В. Пименовой, при конструировании структуры концепта необходимо исследовать весь языковой корпус, в котором концепт получает репрезентацию (лексические единицы, фразеология, паремиология) [17, с. 20].

Совокупность языковых средств, объективирующих концепт, З.Д. Попова и И.А. Стернин определяют номинативным полем. Ученые выделяют в нем (номинативном поле) комплексный характер, включая традиционные структурные группировки лексики (лексико-семантическую группу, лексико-семантическое поле, лексико-фрразеологическое поле, синонимический ряд, ассоциативное поле) в свой состав.

Концепты «бæх», «лошадь» и «horse» имеют обширное и легко выявляемое номинативное поле. Однако в сопоставляемых языках исследуемый нами концепт имеет разную номинативную плотность, т. е. разную степень детальности языкового обозначения $[18$, c. 102].

Опираясь на материал энциклопедических, лексикографических и фразеологических источников, а также фолькллорных и художественных текстов, в осетинском, русском и английском языках были выявлены наиболее значимые смысловые признаки, являющиеся универсальными и относимые нами к ядру исследуемого концепта:

- $\quad$ крупное животное;

- д домашнее животное;

- рабочая лошадь;

- верховое животное;

- $\quad$ упряжное животное;

- $\quad$ быстрое животное;

- $\quad$ животное определенной масти;

- ценное животное;

К периферии исследуемого нами концепта относим следующие смысловые признаки номинативного поля:

- мелкое выносливое животное;

- $\quad$ глупое животное;

- норовистое животное;

- смежная область концептов «лошадь» и «дорога»;

- $\quad$ животное, с которым связаны различные поверия и обряды.

В данной статье мы рассматриваем концептуальный признак «рабочая лошадь», который в сопоставляемых лингвокультурах имеет разную номинативную плотность. Согласно И.А. Стернину, «в акте речи вер-

Чибиров Тимур Николаевич - младший научный сотрудник «Центра изучения скифско-аланских исследований имени Абаева» Владикавказского научного центра Российской академии наук (langless.ru@gmail.com). 
бализуется коммуникативно релевантная часть концепта» [21, с. 50], таким образом ввиду культурных особенностей те или иные фррагменты концепта поразному наполнены содержанием, в результате чего могут иметь разную полевую локализацию.

Признак «рабочая лошадь» условно относим к ядерной части исследуемого нами концепта, однако в сопоставляемых лингвокультурах он достаточно неравномерно представлен. В осетинской языковой картине мира, в отличие от русской и английской, данный признак не так ярко выражен. К тому же нередко носит противоречивый характер, что вызывает сомнения относительно его ядерной природы.

К единицам, прямо выражающим данный признак, относятся: уаргъджын бæх - вьючная лошадь, уæзласæн бæх - ломовая лошадь, уæрдоны бæх упряжная лошадь. В осетинском языке существует также лексема хайуан, описывающая домашних вьючных животных, которая часто употребляется в отношении лошади, выполняющей тяжелые работы.

Несмотря на десицит в осетинском языке лексических единиц (далее ЛЕ), описывающих средства перевозки людей и грузов, в которые запрягается лошадь (в фольклорных текстах лошадь часто представлена как верховая, обладающая высокими скоростными характеристиками), тем не менее жизнь в тяжелых горных условиях заставляет осетин использовать ее в качестве вьючного животного, на что также указывает лексема бæхуаргъ - лошадиный вьюк: «Чидæртæ быдыры хъæуты балхæдтой хор, фрæсæфищæгмæ йæ сластой æххуырсгæ уæрдæтты æмæ йæ ныр хæссыни бæхуаргъæй» - Кое-кто в равнинных селах купил зерно, перевез его через перевал в нанятых повозках, а теперь везет его на лошадиных вьюках [6, с. 94].

В осетинской паремиологии признак «кусæе бæх» («рабочая лошадь») достаточно противоречиво выражен. С одной стороны, в отдельных паремиях отражен образ рабочей лошади: хъæды куыстæн - гал æмæ бæх - «для лесных работ - бык и лошадь» [10, с. 502]. С другой стороны, концепты бæх («лошадь») и куыст («работа»), соприкасаясь друг с другом, выражают признак «несоответствия»: хæрæе кусы, бæх хæры «осел работает, лошадь ест» [10, с. 110]; уæлбæхæй куыстытæ - «работы верхом на коне» [10, с. 119]; уыдон уæлбæхæй хуымгæнджытæ сты - «они верхом на лошади землепашцы» [10, с. 120] (о несерьезных работах).

В подтверждение идеи периферичности признака «кусæе бæх» («рабочая лошадь») приводим стихотворение Сека Гадиева «Рæстæг» («Время»), в котором автор показал привилегированное положение лошадиных (лат. Equidae) в представлении осетин:

Каркæй, кæркгæсæй,

Цъиуæй, цæргæсæй,

Иууылдæр æмгæрттæ.

Бæхæй, хæргæфрсæй,

Уырсæй, сыл ефрсæй,

Иууылдæр æлдæрттæ.

Куры, птичники,

Птицы и орлы,

Все равны друг другу.

Кони, мулы,

Жеребцы, кобылы,

Все они князья.

[3, c. 190]

В осетинских фолььклорных текстах встречаются примеры, где данный признак передается через метафору «запряженная лошадь». Так, в плаче по умершему (хъарæ2), с сожалением говорится о девушках, остающихся без кормильца. Их судьба отождествляется с долей рабочей лошади: Цы мæгуыр сты уыдæттæ дæр! Ифртыгъд бæхау, ифртыгъдæй иы чызджытæ баззайы - Как же жаль и таких девушек, которые оста- ются подобно запряженной лошади [7, с. 15].

В художественных текстах признак «рабочая лошадь» встречается гораздо чаще: Цыппар мæллæ2 бæхы ластой иу гутон - Четыре тощие лошади тянули плуг [1, с. 118];

Бон-изæрмæ ифртыгъдæй

Фыдлæджы бæх фрæкусы.

С утра до вечера запряженной,

Лошадь изверга работает [3, с. 99].

Признак «рабочая лошадь» очень богато представлен в русской картине мира. По мнению Е.А. Ивановой, в русской культуре лошадь в первую очередь символизирует силу, выносливость и трудолюбие [9, с. 11]. Русский язык имеет широкий ряд ЛЕ, содержащих данный признак: битюг - рабочая лошадь-тяжеловоз; водовозка - лошадь, используемая для доставки воды (запряженная в телегу с бочкой); вьючная лошадь - лошадь, используемая для перевозки грузов (вьюков); ломовая лошадь - лошадь, используемая для перевозки грузов; пахотная лошадь - лошадь, используемая в пахотных работах; першерон - лошадьтяжеловоз; рабочая лошадь - лошадь, выполняющая различные виды работ; тяжеловес, тяжеловоз - рабочая лошадь, занимающаяся перевозкой больших грузов и выполнением тяжелых работ.

Говоря о паремиях, содержащих образ рабочей лошади, прежде всего следует упомянуть: старый конь борозды не портит (т. е. в сохе при пашне) [4, с. 382], которая встречается также в английской лингвокультуpe: an old horse doesn't spoil the furrows. Это говорит о том, что образ пахотной лошади близок обеим культурам и имеет давнюю традицию, поскольку идентичность обеих провербий указывает на их происхождение от одного более раннего варианта.

Русская фразеология содержит целый ряд единиц, содержащих указание на данный признак: буровить / вкалывать как конь 'о много, напряженно занимающемся тяжелой, изнурительной работой человеке' [13, с. 284]; как конь загнанный 'о человеке, которого изнурили тяжелой работой и хлопотами' [13, с. 284]; как конь плохой 'о слабом, старом, измученном работой человеке' [13, с. 284]; как ломовой конь 'о здоровом, выносливом, привычном к тяжелому фризическому труду человеке' [13, с. 284]; лобозить як бурый конь 'о много, натужно, с большим напряжением работающем человеке' [13, с. 284]; лютая как конь 'об очень здоровой, работающей женщине' [13, с. 284]; работать как конь 'об очень напряженно, много и тяжело работающем человеке' [13, с. 285].

В русской фразеологии находим еще одну единицу, указывающую на рассматриваемый нами признак: конь еще не валялся, т. е. 'ничего еще не сделано', 'работа еще не начата'. Существует целый ряд трактовок данного фразеологизма, отдельные из которых выражены признаком «работа». В.М. Мокиенко в своем историко-этимологическом справочнике по русской фрразеологии «Почему так говорят?: от авося до ятя» посвящает целую словарную статью данному фрразеологизму. Ссылаясь на академический словарь Грота-Шахматова, ученый подчеркивает, что данная ФЕ отражает русский крестьянский обычай - дать поваляться лошади перед запряжкой, что, согласно поверью, заряжало ее большей энергией на весь день. Однако В.М. Мокиенко не удовлетворяется ни версией крестьянского обычая, ни «гигиенической» процедурой лошади по чистке шерсти. Ученый привлекает этнологические и этнографические данные, указывая 
на мифрологическое происхождение данного фразеологизма, которое связано с целительным валянием коня в утренней росе. Данное «действо», по мнению ученого, представляет собой не просто переход от ночи ко дню, а является своего рода процессом перевоплощения коня, от демонической природы к очищению. В заключение В.М. Мокиенко, говоря об утрате мифологического значения и замене его указанием на крестьянский обряд, объясняет важную роль лошади в домашнем хозяйстве [14, с. 278-285].

Признак «рабочая лошадь» может быть также выражен в паремиологии через указание на груз, элементы конской сбруи (вожжи, хомут, узда, супонь, воз): сколько кобыле ни прыгать, а быть в хомуте [4, с. 40]; сердится кобыла на воз, а прет его под гору и в гору [4, с. 97]; чей конь, того и воз [4, с. 130]; баба с возу - кобыле легче [4, с. 188]; у кобылы хоть семеро жеребят, а хомут свой (о работе) [4, с. 290]; засупонь (зануздай) кобылу под хвостом! [4, с. 358]; сколько кобылка жеребят не рожала, а хомут не миновала [5, с. 16]; похвали клячу, да в соху; лямку три, налегай да при! Кобылку в хомут, а бурлака в лямку [5, с. 17].

Признак «workhorse» в английской лингвокультуре не менее богато представлен в рамках концепта horse. Выражен целым рядом ЛЕ: dray horse, draft / draught horse - ломовая лошадь; dobbin - лошадь, работающая на ферме; driver - тягловая лошадь, приученная к хомуту; pack-horse, sumpter horse - вьючная лошадь; plow / plough horse - лошадь, запряженная в плуг; workhorse - рабочая лошадь. Сюда же мы относим лексемы, описывающие использование лошади в качестве средства транспорта: cab-horse - лошадь, запряженная в наемный экипаж; cart-horse - ломовая лошадь, запряженная в повозку (cart - повозка, телега); carriage horse - лошадь, запряженная в коляску, экипаж; coach horse - сильная ломовая лошадь, запряженная в коляску, экипаж, карету. А также роль лошади в упряжке: fore horse - лошадь, запряженная в экипаж спереди; pole horse (poler), shaft horse, wheel horse (wheeler) - коренная лошадь, коренник.

Признак «рабочая лошадь» находит отражение и в русской литературе. У Л.Н. Толстого в романе «Анна Каренина» мы встречаем выражение "работать, как лошадь»: «Другое немножко неприятное было то, что новый начальник имел уж репутацию страшного человека, встающего в шесть часов утра, работающего, как лошадь, и требующего такой же работы от подчиненных» (Л.Н. Толстой «Анна Каренина») [Толстой. Анна Каренина: с. 409].

Признак «работа» неотделим от признаков «сила», «здоровье»; здесь мы также находим примеры зоометафоры «лошадь» в аспекте ее переноса на человека. В русском: лошадь 'человек, обладающий силой, работоспособностью и т. д.'; лошадиное здоровье 'о хорошем, крепком здоровье'; пить как лошадь 'очень много, в больших дозах', отсюда и лошадиная доза 'о чем-то очень большом' [БТСРЯ, с. 506]. В английском: eat like a horse (букв. есть как лошадь) 'отличаться за- видным аппетитом, есть много и с жадностью'; strong as a horse (букв. силен как лошадь) 'здоров как бык, т. е. имеющий крепкое здоровье'.

Признак workhorse «рабочая лошадь» получает отражение в английской фразеологии, где рабочая лошадь представлена в различных оттенках. Выражение a willing horse (букв. «старательная лошадь») передает положительный, одобрительный оттенок и при переосмыслении характеризует 'человека, охотно взваливающего на себя работу' [11, с. 399], отсюда и паремия: all lay loads on a willing horse (букв. весь груз взваливают на добросовестную лошадь) 'все валят работу на безотказного работника' [20, с. 11]. Английский фразеологизм workhorse (букв. «рабочая лошадка») - 'о человеке выполняющем большую часть работы' [22]. Отсюда и выражение work like a horse (букв. «работать, как лошадь»), соответствующее русскому «работать, как вол» [19, с. 28]. Еще один фразеологизм, иллюстрирующий содержательность данного признака в английской лингвокультуре, - hackwork (букв. «работа наемной лошади») 'тяжелая неинтересная работа', 'халтура' [22].

В отдельных английских фрразеологизмах иллюстрируется плохое обращение с рабочей лошадью, которое впоследствии получило переосмысление: beat / flog a dead horse (букв. «бить / стегать дохлую лошадь») 'заниматься бесполезным делом' [11, с. 397].

Когнитивный признак "workhorse» получает фриксацию на метафооическом уровне, что говорит о фрункциональной значимости данного признака в английской лингвокультуре. Языковая метафора «workhorse» встречается в различных областях человеческой деятельности, восполняя пробелы в терминологии: workhorse 'легкий вертолет или самолет общего назначения' (военная отрасль); 'козлы (для ручной распилки лесоматериалов)' (лесная промышленность).

Еще одним важным свидетельством содержательности данного признака в английской лингвокультуре является упоминание образа рабочей лошади в фольклорных текстах: One morning when he was ploughing his field he had just reached the end of the furrow and was turning the horse round when he looked up and saw a Boggard, standing with his arms folded and feet planted far apart and scowling down at him. - Однажды утром, вспахивая свое поле, он только дошел до края борозды и поворачивал лошадь обратно, как поднял глаза и увидел угрюмо уставившегося на него домового со сложенными руками и широко расставленными ногами $[15$, с. 110$]$

Следует отметить, что среди различных способов структурной организации концептов, когнитивный (концептуальный) признак, являющийся, по М.В. Пименовой, структурной единицей ментального образования, представляет, при конструировании концепта, безусловный интерес, поскольку дает возможность наиболее содержательно описать структуру концепта, а при рассмотрении универсальных концептов позволяет выявить национально-культурную специфику.

\section{ЛИТЕРАТУРА}

1. ÆЕъъуызарты ÆE. Куырды фырт: Роман дыууæ чиныгæй (Агузаров А.T. Сын кузнеца: Роман в двух томах). Дзæуджыхъæу: Ир, 1995. 526 фр.

2. Болдырев Н.Н. Когнитивная семантика [Текст]: Курс пекций по английской филологии. - Тамбов: Изд-во Тамб. ун-та, 2001. Изд. 2-е, стер. 123 c.
3. Гæдиаты С. Уацмыстæ (Гадиев С.Г. Произведения). Дзæуджыхъæу: Иp, 1991. 639 с.

4. Даль В.И. Пословицы русского народа: Сборник. 1. - М.: Худож. лит., 1984. 383 с.

5. Даль В.И. Пословицы русского народа: Сборник. 2. / Послесл. В. Аникина; Худож. Г. Клодт. - М.: Худож. лит., 1984. 399 с. 
6. Дзесты К. Фæндагсар Уастырджи (Дзесов К. Покровитель путников): АЕвзæрст уацмыстæ - Дзæуджыхъæу: Проект-Пресс, 2007. - 327 фь.

7. Зарджытæ, таурæъътæ, æмбисæндтæ (Песни, сказания, пословицы) // Чиныг сарæзта Джыккайты Ш. - Цхинвал: Ирыстон, 1977. 302 с.

8. Иванова С.В. Лингвокультурологический аспект исследования языковых единиц: дис. ... д-ра филол. наук. - Уфра, 2003. 364 c.

9. Иванова E.A. Механизмы актуализации концепта horse в британской лингвокультуре. Дисс... к. фрилол. Н. - Самара, 2010.

10. Ирон диссæгтæ æмæ æмбисæндтæ (Словарь осетинских послович) // Сарæзтой йæ Айларты И., Гæджынаты P., Кцойты Р. - Дзæуджыхъæу: Ир, 2006. 712 фр.

11. Кунин А.В. Англо-русский фразеологический словарь // Лит. ред. М.В. Литвинова. - 4-е изд. - М. Рус. яз., 1984. $994 \mathrm{c}$

12. Маслова В.А. Когнитивная лингвистика: учеб. пособие. - Минск: ТетраСистемс. 2005. 256 с.

13. Мокиенко В.М., Никитина Т.Г. Большой словарь русских народных сравнений. - М.: ОЛМА Медиа Групп, 2008. 800 с. 14. Мокиенко В.М. Почему так говорят? Оm Авося до Ятя:
Историко-этимологический справочник по русской фрразеологии. - СПб.: Норинт, 2004. 512 с.

15. Народные сказки Британских островов. Сборник // Сост. Дж. Риордан. - М.: Радуга, на англ. яз. 1987. 368 с.

16. Пименова М.В. Концепт надежда в русской языковой картине мира // Человек и его язык / Под ред. Е.А. Пименова, М.В. Пименовой. - Кемерово: Графика, 2003. Вып. 4. C. $47-67$.

17. Пименова М.В. Предисловие. / Введение в когнитивную лингвистику. Под ред. М.В. Пименовой. Вып. 4. Кемерово, 2004. $208 \mathrm{c}$.

18. Попова 3.Д., Стернин И.А. Семантико-когнитивный анализ языка. Монографрия. - Воронеж: Истоки, 2007. 250 с. 19. Котий Г.А. Русско-английский словарь крылатых слов и выражений // Под ред. А.С. Дробашенко. 4-е изд. - М.: Наука, 2007. 40 c.

20. Словарь английских послович и фразеологических выражений. Сост. А.А. Хазан. - Смоленск: Русич, 2001. 560 c. 21. Стернин И.А. Концепты и лакуны // Вестник КРСУ, 2016. Том 16. № 8. C. 49-52.

22. ABBYY Lingvo Online Dictionary [Electronic resource] Electronic data. 2013. - Mode of access: http://www.lingvoonline.ru. - Title from the Internet home page.

\title{
THE COGNITIVE SIGN «WORKHORSE» IN THE STRUCTURE OF THE CONCEPT «HORSE» IN THE OSSETIAN, RUSSIAN AND ENGLISH LINGUOCULTURES

\author{
Chibirov T.N.
}

Junior research scientist of «The Abaev's Centre of Scythian-Alanian Studies» of Vladikavkaz Scientific Centre of the RussianAcademy Of Sciences (langless.ru@gmail.com).

\begin{abstract}
In this article different ways of the concept structure organizing are being considered, among which the author underlines the cognitive sign, that, according to M.V. Pimenova, is a structural unit of the mental structure. In terms of the concept "horse" in the Ossetian, Russian and English linguocultures the cognitive sign "workhorse" is described, which consideration has revealed its unequal representation in the above-mentioned linguocultures. Comparatively rich lexical and phraseological material of the Russian and English languages representing the sign "workhorse" indicates that it belongs to the core, whereas in Ossetic there is a certain lack of this sort of vocabulary, and a number of identified phraseological units contain a specific connotation "frivolous works".

Keywords: concept "horse", cognitive sign, national specific, field structure of the concept, structure of the concept, core periphery.
\end{abstract}

\section{REFERENCES}

1. AEg"uyzarty AE. Kuyrdy fyrt: Roman dyuuæ chinygæy (Aguzarov A.T. Syn kuznetsa: Roman v dvukh tomakh). - Dzæudzhykh"æu: Ir, 1995. 526 f

2. Boldyrev N.N. Kognitivnaya semantika [Tekst]: Kurs lektsiy po angliyskoy filologii. - Tambov: Izd-vo Tamb. un-ta, 2001. Izd. 2-e, ster. $123 \mathrm{~s}$

3. Gædiaty S. Uatsmystæ (Gadiev S.G. Proizvedeniya). Dzæudzhykh"æu: Ir, 1991. 639 s.

4. Dal' V.I. Poslovitsy russkogo naroda: Sbornik. 1. - M.: Khudozh. lit., 1984. $383 \mathrm{~s}$.

5. Dal' V.I. Poslovitsy russkogo naroda: Sbornik. 2. / Poslesl. V. Anikina; Khudozh. G. Klodt. - M.: Khudozh. lit., 1984. - 399 s. 6. Dzesty K. Fændagsar Uastyrdzhi (Dzesov K. Pokrovitel putnikov): ÆEvzærst uatsmystæ - Dzæudzhykh"æu: ProektPress, 2007. - $327 \mathrm{f}$.

7. Zardzhytæ, tauræg"tæ, æmbisændtæ (Pesni, skazaniya, poslovitsy) // Chinyg saræzta Dzhykkayty Sh. - Tskhinval Iryston, 1977. $302 \mathrm{~s}$.

8. Ivanova S.V. Lingvokul'turologicheskiy aspekt issledovaniya yazykovykh edinits: dis. ... d-ra filol. nauk. - Ufa, 2003. 364 s. 9. Ivanova E.A. Mekhanizmy aktualizatsii kontsepta horse $v$ britanskoy lingvokul'ture. Diss... k. filol. N. - Samara, 2010. 10. Iron dissægtæ æmæ æmbisændtæ (Slovar' osetinskikh poslovits) // Saræztoy yæ Aylarty I., Gædzhynaty R., Ktsoyty R. - Dzæudzhykh"æu: Ir, 2006. $712 f$.

11. Kunin A.V. Anglo-russkiy frazeologicheskiy slovar' // Lit. red. M. V. Litvinova. - 4-e izd. - M. Rus. yaz., 1984. 994 s.
12. Maslova V.A. Kognitivnaya lingvistika: ucheb. posobie. Minsk: TetraSistems. 2005. $256 \mathrm{~s}$.

13. Mokienko V.M., Nikitina T.G. Bol'shoy slovar' russkikh narodnykh sravneniy. - M.: OLMA Media Grupp, 2008. $800 \mathrm{~s}$ 14. Mokienko V.M. Pochemu tak govoryat? Ot Avosya do Yatya: Istoriko-etimologicheskiy spravochnik po russkoy frazeologii. SPb.: Norint, 2004. $512 \mathrm{~s}$.

15. Narodnye skazki Britanskikh ostrovov Sbornik // Sost. Dzh. Riordan. - M.: Raduga, na angl. yaz. 1987. 368 s.

16. Pimenova M.V. Kontsept nadezhda $v$ russkoy yazykovoy kartine mira // Chelovek i ego yazyk / Pod red. E.A. Pimenova, M.V. Pimenovoy. - Kemerovo: Grafika, 2003. Vyp. 4. S. 47-67.

17. Pimenova M.V. Predislovie. / Vvedenie $v$ kognitivnuyu lingvistiku. Pod red. M.V. Pimenovoy. Vyp. 4. Kemerovo, 2004. $208 \mathrm{~s}$.

18. Popova Z.D., Sternin I.A. Semantiko-kognitivnyy analiz yazyka. Monografiya. - Voronezh: Istoki, 2007. 250 s.

19. Kotiy G.A. Russko-angliyskiy slovar' krylatykh slov i vyrazheniy // Pod red. A.S. Drobashenko. 4-e izd. - M.: Nauka, 2007. $40 \mathrm{~s}$.

20. Slovar' angliyskikh poslovits i frazeologicheskikh vyrazheniy. Sost. A.A. Khazan. - Smolensk: Rusich, 2001. 560 s.

21. Sternin I.A. Kontsepty i lakuny // Vestnik KRSU, 2016. Tom 16. № 8. S. 49-52.

22. $A B B Y Y$ Lingvo Online Dictionary [Electronic resource] Electronic data. 2013. - Mode of access: http://www.lingvoonline.ru. - Title from the Internet home page. 